\title{
Evaluation of fine needle aspiration cytology of thyroid lesions based on Bethesda system of reporting cytopathology
}

\author{
Chandan R.H. ${ }^{1}$, Arathi S. ${ }^{2}$, Jigalur P. ${ }^{3}$, Giriyan S.S. ${ }^{4}$ \\ ${ }^{1}$ Dr. Rajesh H. Chandan, Associate Professor, ${ }^{2}$ Dr. Arathi S., Assistant Professor, ${ }^{3}$ Dr. Parvati Jigalur, Assistant \\ Professor, ${ }^{4}$ Dr Sujata S. Giriyan, Professor and HOD, all authors are affiliated with Department of Pathology, KIMS, \\ Hubballi, Karnataka, India.
}

Corresponding Author: Dr. Arathi S., Assistant Professor, Department of Pathology, KIMS, Hubballi, Karnataka, India. E-mail: docartishree@rediffmail.com

\begin{abstract}
Introduction: FNAC is the first line diagnostic test for evaluation of thyroid lesions. Identification of cytological features is key element in diagnosing thyroid lesions, which will reduce the number of unnecessary surgeries of thyroid nodules. Bethesda system of reporting helps the clinicians to take appropriate therapeutic intervention. Aim: To study the cytomorphological features of various thyroid lesions and to categorize as per Bethesda system proposed by NCI Bethesda USA in 2007. Materials and Methods: This is a prospective study of cases of thyroid lesions received in cytology section of Department of Pathology, KIMS Hubballi, during Jan 2017 to Dec 2017. FNAC was performed and reported according to Bethesda system. Results: FNAC was performed on 370 cases of thyroid lesions. Maximum number of cases were in the age group of 21-30 years.Male to female ratio was 1: 9.27. Maximum number of cases presented in less than 6 month duration. Most of the cases presented with swelling in the neck. Out of the total 370 cases, 351were benign lesion, 6 cases were malignant, 8 were unsatisfactory, 3 were follicular neoplasm/suspicious of follicular neoplasm, 1 was suspicious for malignancy and 1 was follicular lesions of undetermined significance. Out of 351 benign lesions, commonest was colloid/ nodular goiter, followed by lymphocytic/Hashimotos thyroiditis. Conclusion: FNAC is the most simple, rapid and safe diagnostic test for evaluation of thyroid lesions with high degree of accuracy. Bethesda system of reporting thyroid cytopathology is very useful as it is systematic and standardized and hence provides better communication between clinicians and cytopathologist for appropriate therapeutic intervention.
\end{abstract}

Keywords: Bethesda system, Fine needle aspiration cytology, Thyroid lesion

\section{Introduction}

Thyroid diseases are among the commonest endocrine disorders worldwide and in India.According to various studies on thyroid disorder it has been estimated that about 42 million people in India suffer from thyroid disorders [1]. The enlargement of thyroid gland is seen in $3-5 \%$ of the population [2]. The presentation of the thyroid gland disease is widely varied. The course of the treatment and follow up rests on the proper diagnosis of the disorder with specific investigations [3].

The accuracy of clinical, biochemical and radiological investigations in distinguishing between benign and malignant nodules is rather poor [4]. FNAC is the first line diagnostic test for evaluation of thyroid lesions. It is accepted globally as the best screening tool to differentiate neoplastic and nonneoplastic lesion.

\footnotetext{
Manuscript received: $1^{\text {st }}$ January 2019

Reviewed: $12^{\text {th }}$ January 2019

Author Corrected: $18^{\text {th }}$ January 2019

Accepted for Publication: $23^{\text {rd }}$ January 2019
}

The cytological features of nonneoplastic disorders of thyroid have a good amount of overlap between them and with few neoplastic lesions as well, thus leading to wrong interpretation and possible inappropriate management of the patients. Identification of cytological features is key element in diagnosing thyroid lesions by FNA procedurewhich will reduce the number of unnecessary surgeries of thyroid nodules [5]. The use of FNAC resulted in a decrease in numberof patients who underwent surgical treatment by $25-50 \%$ while increasing percentage of malignant results in the operated group of patients [6]. USG guided FNAC is becoming increasingly popular as it enhances the value of FNA diagnostic accuracy [7]. To address terminology related issues, National Cancer Institute hosted the Thyroid FNA state of the science conference and proposed Bethesda system for reporting of thyroid cytopathology [8]. A standardized reporting format so as to communicate to the clinician and to help in clinical management is offered by Bethesda system [9]. 


\section{Original Research Article}

\section{Aim}

1) To study the cytomorphological features of various thyroid lesions.

2) To categorize as per TBSRTC of Bethesda system.

\section{Materials and Methods}

This is a prospective study done in cytology section of department of pathology, KIMS Hubballi, during Jan 2017 to Dec 2017.

All the cases of thyroid swelling were included in the study and all the cases having neck swelling other than thyroid were excluded from the study. Clinical history, physical examination and ultrasound findings of these cases were noted. FNAC was performed by conventional method of palpation or with USG using 22 gauge needle.
The patient was made to lie down in supine position with neck hyper extended keeping pillow under the neck so as to expose the gland more prominently. The patient was asked to refrain from swallowing during the procedure. The skin overlying the swelling was cleaned with spirit. The needle was inserted in to the nodule and plunger was retracted to create a vacuum in the syringe. The needle was moved back and forth gently within the lesion,all the time maintaining pressure in the syringe. The plunger was then released.

The needle was withdrawn from the thyroid and the material was taken on the slide.Direct smears were prepared and were either air dried and stained with Wrights stain or fixed in alcohol and stained with $\mathrm{H}$ \& E. Smears were evaluated and diagnosis assigned according to the Bethesda system.

\section{Results}

FNAC was performed on 370 cases of thyroid lesions. Age of the patients ranged from 2 to 82 years. Maximum number of cases were in the age group $21-30$ years in present study. In females, maximum number of cases were in age group 21-30 years. In males, maximum number of cases were in age group 41-50 years. Out of total 370 cases, 334 cases were female and 36 cases were males.Male to female ratio was 1:9.27. Duration of complaints for thyroid lesionsin the present study was up to 6 months in 232 cases (62.7\%), 6 months -1year in 45 cases $(12.16 \%), 1$ - 10 years in 68 cases $(18.38 \%)$, more than 10 years in 10 cases $(2.7 \%)$ and those noticed on examination were $15(4.05 \%)$ cases. Maximum number of cases presented in less than 6 months duration. Most of the cases presented with swelling in the neck 355 cases $(95.95$ $\%$ ), followed by loss of weight and loss of appetite, 30 cases(8.11\%) each, palpitation and anxiety in 29 cases( $7.84 \%)$, dysphagia in 28 cases $(7.57 \%)$, weight gain in 10 cases $(2.7 \%)$ dyspnea in 6 cases $(1.62 \%)$ and hoarseness of voice in 4 cases $(1.08 \%)$.

On examination largest swelling measured 10x15 cm and smallest measured 1x1 cm. Diffuse swelling was seen in 150 cases (40.54\%) and nodular swelling was seen in 220 cases $(59.46 \%)$. The swelling was mobile and firm in 368 cases $(99.46 \%)$. Total number of thyroid FNAC were 370.In our study we did not encounter any complication. Nature of the aspirate was hemorrhagic in 262 cases $(70.81 \%)$, brown coloured fluid in 90 cases $(24.3 \%)$ and grey white material in ten cases $(2.7 \%)$. The cytological features were categorized according to TBSRTC into six categories. Out of these, $351(94.86 \%)$ were benign lesions, $6(1.62 \%)$ cases were malignant, $8(2.16 \%)$ were unsatisfactory, $3(0.81 \%)$ were follicular neoplasm/suspicious of follicular neoplasm, suspicious for malignancy and follicular lesions of undetermined significance were one $(0.27 \%)$ each.

Table-1: Cytological diagnosis of thyroid lesions as per Bethesda system in the present study

\begin{tabular}{|c|l|c|c|}
\hline Category & Cytological Diagnosis & No.of Cases & $\%$ \\
\hline I. & Unsatisfactory & 8 & 2.16 \\
\hline II. & Benign follicular lesion & 351 & 94.86 \\
\hline III. & Atypia of follicular lesion of undetermined significance & 1 & 0.27 \\
\hline IV. & Follicular neoplasm/ suspicious of follicular neoplasm & 3 & 0.81 \\
\hline V. & Suspicious for malignancy & 1 & 0.27 \\
\hline VI. & Malignant tumors & 6 & 1.62 \\
\hline & Total & $\mathbf{3 7 0}$ & $\mathbf{1 0 0}$ \\
\hline
\end{tabular}

Maximum number of cases reported on cytology were benign thyroid lesions 351 cases (94.86\%). Out of 351 benign lesions, commonest was colloid/ nodular goiter 205 cases (58.4\%). All 205 cases showed follicular cells in clusters or singles in variable proportion. Hurthle cell change were seen in 50 cases (24\%), foamy macrophages in 57 cases $(27.8 \%)$, moderate to abundant colloid in 145 cases $(70.73 \%)$ and scant colloid in 60 cases $(29.3 \%)$. 


\section{Original Research Article}

Lymphocytic/Hashimotos thyroiditis was diagnosed in 105 cases (29.91\%) showed polymorphic population of lymphoid cells in all the cases with lymphocytic infiltration of follicles in 93 cases $(88.57 \%)$ and hurthle cell changes in 102 cases (97\%). Nodular goiter with secondary hyperplasia was diagnosed in 30 cases $(8.55 \%)$ and primary hyperplasia in 10 cases $(2.85 \%)$. Smears of cases of hyperplasia showed hyperplastic follicular cells with fire flare appearance. Granulomatous/subacute thyroiditis was identified inone case (0.28\%). Malignancy was found in 6 cases (1.62\%). Out of these, 5 cases were diagnosed as papillary carcinoma which showed cells arranged in papillary pattern in all the cases. Intranuclear inclusion and grooving was seen in 3 cases with scant colloid in 2 cases. One case of medullary carcinoma was identified. The smear showed hyper cellular aspirate with dispersed plasmacytoid and spindle shaped cells having stippled chromatin.

\section{Discussion}

In the evaluation of individual patients with nodular disease, there are occasions when either palpation or ultrasound guided FNA of a thyroid nodule are reasonable to perform.Palpation guided FNA can be performed with high levels of success in specific circumstances [8]. Palpation guided FNAC plays a significant role in the diagnosis of thyroid lesion due to its simplicity and low cost. The procedure is regarded as valuable method of distinguishing between malignant from those of benign lesions that can be followed upclinically. Majority of thyroid swellings are nonneoplastic and do not require surgical intervention. Less than $5 \%$ of thyroid nodules are malignant [10].

The available initial screening test for thyroid lesions include ultrasound, thyroid antibody levels, FNAC and radionuclide scan .Among them FNAC is considered as the best initial diagnostic test which help to identify various thyroid lesions with high degree of accuracy.Therefore a thorough cytological evaluation and an integrated approach are necessary to pick up correct diagnosis and to avoid unnecessary surgeries [11].

In the present study, commonest age group was 21-30 years, with mean age of 37.6 \%.Similar finding were noted in study done by Dimple et al with mean age of 37.2 years [12]. Shivani et al noted majority of the patients in the age group 31-40 years with mean age of 33.69 years. In our study there was female preponderance with male to female ratioof 1:9.27 which is similar to the study done by Dimple et al with male to female ratio being 1:9 [12]. Shivani et al also noted $86 \%$ females and $14 \%$ male, with male to female ratio being 1:6.14 [3]. Obaid et al and most of the other studies also showed female predominance [9].

The duration of swelling being present for less than one year in 277 cases (74.86 \%) whichis similar to the study done by Reetika et al (78\%) [13]. Patients presented with history of neck swelling for more than one year in $41.66 \%$ in study by Shaista et al [14]. Most of the casesin our study presented with swelling in the neck 355cases (95.95\%), similar to study done by Shaista et al (94.44\%) and Reetika et al (98.5\%) followed by other symptoms [13,14].

Local examination findings were comparable with study done by Reetika et al which showed diffuse swelling in 38.5\%, nodular in $61.59 \%$, mobile and firm in $98.5 \%$ of cases [13]. Shaista et al noted diffuse in $48.8 \%$, nodular in $51.11 \%$, mobile in $96.66 \%$ cases and restricted mobility in $4.44 \%$ cases [14].

Cytological evaluation included various parameters likesample adequacy, background, cellular arrangement / pattern, cellular details including nuclear features [5]. A uniform reporting system for thyroid FNA will facilitate effective communication among cytopathologist, endocrinologist, radiologists and surgeons [15]. The Bethesda system of reporting thyroid cytopathology established a uniform tiered reporting system.

It offers six diagnostic categories.Category I includes nondiagnostic or unsatisfactory samples consisting of only cyst fluid or virtually acellular specimen. Category II includes benign lesions consistent with benign follicular nodule, lymphocytic/Hashimoto's thyroiditis, granulomatous /subacute thyroiditis and others.Category III includes atypia of follicular lesions of undetermined significance.

Category IV includes follicular neoplasm/ suspicious of follicular neoplasm. Category Vconsists of cases suspicious for malignancy. Category IV includes malignant cases like papillary thyroid carcinoma, poorly differentiated carcinoma, medullary thyroid carcinoma, undifferentiated carcinoma, squamous cell carcinoma, carcinoma with mixed features, metastatic carcinoma and NHL. Each category has implied cancer risk which ranges from $0-3 \%$ for benign category to virtually $100 \%$ for malignant category [16]. 


\section{Original Research Article}

Adequacy of thyroid FNA is defined by both the quantity and quality of the cellular and colloid component. Inadequacy rate in our study was $2.16 \%$ which was comparable with Dimple and Mondal etal [17]. Aliet al suggested that nondiagnostic category must be less than $10 \%$. Other published studies show inadequate sample range between 2 and $20 \%$ [18]. Proper sampling from representative site is important for an accurate diagnosis. Most of the authors recommend 4-5 smears from different areas of nodule with 2-5 passes are a reasonable number of passes to ensure an adequate sample [19].

Comparison of neoplastic to nonneoplastic lesions on FNAC is found to be 1:34 in our study, and it was 1:14 by Obaid et al. Hyang-Mi Ko et al in 2003 found it to be 1:19.2 [20]. In nonneoplastic group colloid goiter was seen in 58\% cases in the present study similar to Reetika et al 53\% [13].

Table-2: Comparison of distribution of cases according to TBSRTC

\begin{tabular}{|c|c|c|c|c|c|c|c|c|}
\hline & Study & Year & I & II & III & IV & V & VI \\
\hline 1 & Yang et al & 2007 & 10.4 & 64.6 & 3.2 & 11.6 & 2.6 & 7.6 \\
\hline 2 & Yassa et al & 2007 & 7 & 66 & 4 & 9 & 9 & 5 \\
\hline 3 & Mondal et al & 2013 & 1.2 & 87.5 & 1 & 4.2 & 1.4 & 4.7 \\
\hline 4 & Mehra (21) & 2015 & 7.2 & 80 & 4.9 & 2.2 & 3.6 & 2.2 \\
\hline 5 & Dimple et al & 2015 & 3.33 & 65.83 & 7.5 & 18.33 & 1.66 & 3.35 \\
\hline 6 & Present & 2017 & 2.16 & 94.86 & 0.27 & 0.81 & 0.27 & 1.62 \\
\hline
\end{tabular}

In all the above studies, benign category showed highest number of cases. According to Jo et al, most of these studies have been done in tertiary care centre, where patient mainly come on referral basis [22]. It was more higher in the present study similar to Obaid et al, which can be attributed to the fact that our institute despite being tertiary care centre, not only caters patient on referral basis ,but also patients coming directly without referral representing the general population.

The cases of AFLUS, suspicious for follicular neoplasm and suspicious for malignancy was lower and comparable with study done by Mondol et al, which can be because of ultrasound guided FNAC being done in cases of smaller thyroid nodules [17].

Of the 351 cases of benign lesions, the commonest was nodular goiter diagnosed in 205 cases (58.4\%). Abundant colloid and a relatively small number of both involutional and hyperplastic follicular epithelial cells are most characteristic and comparable to Shaista et al 58.88\%. Lymphocytic /Hashimotos thyroiditis was diagnosed in 105 cases (29.91\%) comparable to study done by Reetika et al $21 \%$. It is the second most common thyroid lesion next to colloid goiter in most of the studies [13].

\section{Conclusion}

FNAC is the most simple, rapid and safe diagnostic test for evaluation of thyroid lesions. It helps to distinguish neoplastic from nonneoplastic lesions with high degree of accuracy. Bethesda system of reporting thyroid cytopathology is very useful as it is systematic and standardized and hence provides better communication between clinicians and cytopathologist for appropriate therapeutic intervention.

Findings: Nil; Conflict of Interest: None initiated Permission from IRB: Yes

\section{References}

1. Unnikrishnan AG, Menon UV. Thyroid disorders in India: An epidemiological perspective. Indian J Endocrinol Metab. 2011 Jul; 15 (Suppl 2):S78-81. doi: 10.4103/2230-8210.83329.
2. Bouq YA, Gaffer H. The Current Pattern of Surgically treated Thyroid diseases in the Medinah region of Saudi Arabia. J K Practitioner 2006;13 (1):914.

3. Shivani Nautiyal, Alok Jain .Fine needle aspiration cytology accuracy in diagnosis of thyroid lesions:a comparative study with histopathological examination of thyroid swellings. Int J Otorhinolaryngol Head Neck Surg.2018 Jul;4(4):1002-1007.

4. Orell SR, Sterett OF. Thyroid gland. In: Fine needle aspiration cytology, 5th ed, London, Churchill Livingstone, 2012; 118- 149.

5. Purushotham K, Sowmya R. Cytological features of nonneoplastic lesions of thyroid: An overview. Sciences Journal mar 2013; 3 (1). 
6. Yassa L, Cibas ES, Benson CB, et al. Long-term assessment of a multidisciplinary approach to thyroid nodule diagnostic evaluation. Cancer. 2007 Dec 25;111(6):508-16.DOI:10.1002/cncr.23116

7. Syed Obaid, Anand Auti. The reliability of FNAC in diagnosis of thyroid swelling. International Surgery Journal .2017 Dec;4 (12):3827-3832.

8. Baloch ZW, Cibas ES, Clark DP, et al. The National Cancer Institute Thyroid fine needle aspiration state of the science conference: a summation. Cytojournal. 2008 Apr 7;5:6. doi: 10.1186/1742-6413-5-6.

9. Wang HH. Reporting thyroid fine-needle aspiration: literature review and a proposal. Diagn Cytopathol. 2006 Jan;34 (1): 67-76. DOI: 10.1002/dc. 20400

10. Sclabas GM, Staerkel GA, Shapiro SE, et al. Fineneedle aspiration of the thyroid and correlation with histopathology in a contemporary series of 240 patients. Am J Surg. 2003 Dec;186(6):702-9; discussion 709-10.

11. BN Gayatri, R Kalyani, Prasad KK. Fine needle aspiration cytology of Hashimoto's thyroiditis-A diagnostic pitfall with review of literature. J Cytol. 2011Oct-Dec; 28 (4):210-213.

12. Dimple $\mathrm{M}$, Anita A $\mathrm{M}$, Mahanta $\mathrm{K}$, Andola, Anuradha G Patil. A Clinico-Cytological Study of Thyroid Lesions in a Tertiary Care Centre in North Karnataka with Thyroid Function Test Correlation. National Journal of Laboratory Medicine. 2016 Oct, 5(4)12-15.

13. Sharma R, Verma N, Kaushal V, et al. Diagnostic accuracy of fine-needle aspiration cytology of thyroid gland lesions: A study of 200 cases in Himalayan belt. J Cancer Res Ther. 2017 Jul-Sep;13(3):451-455. doi: 10.4103/0973-1482.164702.

14. Shaista Mushtaq Hamdani, Ruby Reshi. Cytodiagnosis of thyroid lesions with histopathological correlation and evaluation of discrepant cases. International Journal of Medical Science and Public Health, 2015; 4 (8):1.80-1085.

\section{Original Research Article}

15. Park JW, Yoo JS, Yun JK, et al. An online questionnaire survey on preferred timing for the diagnosis and management of thyroid carcinoma in general population in Korea. Ann Surg Treat Res. 2016 Jun; 90 (6): 297-302. doi: 10.4174/astr.2016.90.6.297. Epub 2016 May 30.

16. Ali.Z. Syed, Cibas. S. Edmund. The Bethesda System for reporting thyroid cytopathology, Springer, 2010.

17. Mondal SK, Sinha S, Basak B, et al. The Bethesda system for reporting thyroid fine needle aspirates: A cytologic study with histologic follow-up. J Cytol. 2013 Apr;30 (2):94-9. doi: 10.4103/0970-9371.112650.

18. Yang J, Schnadig V, Logrono R, et al. Fine-needle aspiration of thyroid nodules: a study of 4703 patients with histologic and clinical correlations. Cancer. 2007 Oct 25;111(5):306-15. DOI:10.1002/cncr.22955

19. Richa Bhartiya, Mahasweta Mallik, BN Prasad. Evaluation of thyroid lesions by fine needle aspiration cytology based on Bethesda System for reporting thyroid cytopathology classification among the population of South Bihar. Indian J Med Paediatr Oncol. 20016 Oct-Dec;37(4):265-270.

20. Ko HM, Jhu IK, Yang SH, et al. Clinicopathologic analysis of fine needle aspiration cytology of the thyroid. A review of 1,613 cases and correlation with histopathologic diagnoses. Acta Cytol. 2003 Sep-Oct;47 (5):727-32.DOI:10.1159/000326596

21. Mehra P and Verma AK. Thyroid cytopathology reporting by Bethesda System: A two year prospective in an academic Institution. Pathology Research International. 2015, 11 pages, 2015.doi:10.1155/2015/ 240505M.

22. Jo VY, Stele EB, Hanley KZ. Malignancy risk for Fine needle aspiration of thyroid lesions according to Bethesda System for reporting thyroid cytopathology. Am J Clin Pathol2010;134:450-456.

\section{How to cite this article?}

Chandan R.H., Arathi S., Jigalur P., Giriyan S.S. Evaluation of fine needle aspiration cytology of thyroid lesions based on Bethesda system of reporting cytopathology. Trop J Path Micro 2019;5(1):26-30.doi:10.17511/jopm.2019.i01.05. 